\title{
MASSIVE EDEMA OF OVARY-PSEUDOTUMOR: A CASE REPORT
}

\section{Dr Shreya Chinchoriya* \\ Dr Sandeep Pophale}

\section{M.S. Obstetrics and Gynaecology, Senior Resident. ${ }^{*}$ Corresponding Author \\ M.S. Obstetrics and Gynaecology , Associate Professor ,Diploma in Advanced Gynaec. Endoscopic surgery and Diploma in ART and ICSI.Dept of Obstetrics and Gynaecology , Tertiary care centre, Mumbai.}

\section{ABSTRACT}

Massive ovarian oedema is defined by WHO as formation of tumour like enlargement of one or both ovaries by oedema fluid in the stroma It is a benign lesion with age distribution varying from a neonate at six months of age to postmenopausal women up to 60 -years-old. The differential diagnosis are ovarian fibromatosis, ovarian fibroma, sclerosing stromal tumour and ovarian myxoma. The common management of massive oedema of ovary is unilateral salpingo-oophorectomy, as the lesion is mistaken for primary ovarian neoplasm at laparotomy. Diagnosing MOE is of great importance to prevent unnecessary aggressive treatment in young patients to prevent infertility .We report this case of Massive Oedema of Ovary for its uncommonness.

\section{KEYWORDS : massive edema, ovary , benign}

\section{Case Report}

A 15-year-old unmarried girl presented with chief complaint of pain in right side of abdomen since 15 days and irregular menses since 5-6 months. There were no aggravating or relieving factors for the pain and it was not associated with vomiting or giddiness. The patient has attained menarche at the age of 13 years and her present irregular cycles were associated with pain and clots Per-abdominal examination revealed a mobile, mass of about $10 \times 7 \mathrm{~cm}$ on right side,arising from pelvis ? ovarian mass. Local examination revealed intact hymen.

Ultrasound examination of abdomen and pelvis revealed uterus 7.1 x3.3 x $4.9 \mathrm{cms}$.Right sided multi cystic lesion $1 \mathrm{~lx}$ $9.6 \times 10.5 \mathrm{cms}$, right ovary not seen separately USG $(A+P)$ suggestive of UT $8.7 \times 4.2 \times 2.9 \mathrm{cms}$,ET not measurable, right ovary $13.4 \times 8.2 \times 8.7 \mathrm{cms}$ smooth margins, ovarian stroma markedly hyperechoic with multiple cystic blebs at periphery and within stroma. Increased vascularity possibly reactive hyperemia due to partial torsion ,minimal ascites MRI suggestive of swollen edematous torsed right ovary Patient was given two packed cell volume transfusion on hb $6.6 \mathrm{gm} \%$.post blood transfusion haemoglobin was $7.5 \mathrm{gm} \%$ Patient underwent Laparoscopic cystectomy with right ovariectomy Intraoperative findings were right ovarian cyst of about $15 \times 10 \times 8 \mathrm{cms}$ with right fallopian tube adherent to lesion. Left ovary bulky and multiple follicles were noted.Cyst aspiration was done and sent for fluid cytology and culture sensitivity, reports revealed no cells or organsims.Part of cyst wall excised and sent for frozen section which was suggestive of ovarian stroma and no evidence of malignancy.

The specimen was sent for histopathological examination and was suggestive of MASSIVE EDEMA OF OVARY WITH FOLLICULAR CYSTS.Massive edema with widely spaced stromal cells and few leutinised cells.Also seen were multiple cysts ,occasional containing proteinaceous fluid.No evidence of neoplastic lesion seen.

\section{DISCUSSION}

Massive Edema of Ovary was first described by Kalstone et al., in 1969 [1]. It frequently occurs in young women between the age group of 6-33 years with an average age of 21 years [2].

The patients usually present with acute abdominal pain. Rarely, irregular menstruation and ascites (till date only one case is reported)can be a presenting feature. A palpable adnexal mass or virilisation can also be seen [3-5].
Our patient presented with irregular cycles with right abdominal pain, ascites and supra-pubic mass. There were no signs of virilisation.

Majority of ovarian oedema are unilateral (85\%) \& most involve right ovary , so is in this case[6]. Massive ovarian oedema can occur as primary or secondary condition [7]. Primary oedema occurs when the ovary is not diseased and when there is torsion or twisting of the ovarian pedicle to the degree that it interferes with the venous drainage leading to oedema and does not affect the arterial blood flow [7]. Secondary ovarian oedema occurs in a unhealthy ovary . [7]. Praveen et al., from $1969-2011$, studied a total of 177 cases of massive ovarian oedema were identified [8].

In spite of advanced technology it is difficult to diagnose massive oedema of ovary pre-operatively with imaging techniques. Majority of cases were reported as non-specific heterogenous complex ovarian mass ultrasonographically mirroring a neoplastic condition $[6,9]$.

Frozen section is valuable during the time of surgery [8]. In our case MOE was suspected but showed start of gangrenous changes and hence detorsion or other conservative management could not be done and cystectomy with ovariectomy was performed.

The ovarian lymph contains among others; hormones including progesterone, estradiol and inhibin that are transferred back to the ovarian arteries via retrograde transfer and then they promote the feedback in the hormonal regulation of the ovary $[10,11]$.

Being a minimal invasive surgery patient had minimal morbidity and was relieved of pain abdomen. The patient was given oral contraceptive pills for next 3 months.

\section{CONCLUSION}

Management of massive edema of ovary should be conservative ,trying to preserve for fertility and should be kept in mind as a differential diagnosis to avoid unnecessary hysterectomy with salpingo-oophorectomy or oophorectomy as it is a non neoplastic condition. frozen section is of utmost importance during surgical management of such adnexal masses while it is being missed despite well developed imaging modalities.

\section{REFERENCES}


[1] Kalstone CE, Jaffe RB, Abell MR. Massive oedema of the ovary simulating fibroma. Obstet Gynecol. 1969;34:564-71. [PubMed]

[2] WHO classification of tumours, Tumours of Breast and Genital Organs 2003, IARC Press, page 190

[3] Mohan H, Mohan P, Bal A, Tahlan A. Massive Ovarian Oedema: Report of two cases. Arch Gynecol Obstet. 2004;270:199-200. [PubMed]

[4] Rosai J. Rosai and Ackerman's Surgical Pathology. 9th ed. Philadelphia: Elsevier Inc: 2004 pp. 1649-1736.

[5] Clement PB. Blaustin's Pathology of the Female Genital Tract. 5th ed. New York: Springer-Verlag New York Inc; 2002. Non neoplastic lesions of ovary. In Kurman RJ (Ed) pp. 699-703.

[6] Roberts CL, Weston MJ. Bilateral Massive Ovarian Oedema: a case report. Ultrasound Obstet Gynecol. 1998;11:65-67. [PubMed]

[7] Daboubi MK, Khreisat B. Massive ovarian oedema: literature review and case presentation. Eastern Mediterranean Health Journal. 2008;14(4):972-79. [PubMed]

[8] Praveen RS, Pallavi VR, Rajashekar K, Usha A, Umadevi K, Bafna UD. A clinical update on massive ovarian oedema - a pseudo tumour? E cancer medical science. 2013;7:318. [PMC free article] [PubMed]

[9] Shirk JO, Copas PR, Kattine AA. Massive Ovarian oedema in a menopausal woman. A case report. J Reprod Med. 1996;41(5):359-62. [PubMed]

[10] Umesaki N, Tanaka T, Miyama M, Kawamura N. Sonographic characteristics of massive ovarian oedema. Ultrasound Obstet Gynecol. 2000;16(5):479-81. [PubMed]

[11]. Stefanczyk-Krzymowska S, Krzymowski T, Wasowska B, Chlopek J. Retrograde transfer of ovarian steroid hormones to the ovary in the porcine periovarian vascular complex. Exp Physiol. 2002;87(3):361-71. doi: 10.1113/eph8702338. [PubMed] [Cross Ref] 